\title{
Prevalence of chronic obstructive pulmonary disease among adult male cigarettes smokers: a community-based study in Jordan
}

This article was published in the following Dove Press journal: International Journal of COPD

17 July 2014

Number of times this article has been viewed

\author{
Mousa Al Omari' \\ Basheer Y Khassawneh ${ }^{2}$ \\ Yousef Khader' \\ Ali Shakir Dauod' \\ George Bergus ${ }^{3}$ \\ 'Department of Community \\ Medicine, Public Health and Family \\ Medicine, Faculty of Medicine, \\ Jordan University of Science and \\ Technology, ${ }^{2}$ Department of Internal \\ Medicine, Faculty of Medicine, Jordan \\ University of Science and Technology, \\ Irbid, Jordan; ${ }^{3}$ Department of Family \\ Medicine, Carver College of Medicine, \\ University of lowa, lowa City, IA, USA
}

Correspondence: Basheer Y Khassawneh Department of Internal Medicine, Faculty of Medicine, Jordan University of Science and Technology, PO Box 3030, Irbid 221 10, Jordan Tel +962795449333

Email basheerk@just.edu.jo

\begin{abstract}
Chronic obstructive pulmonary disease (COPD) is a leading cause of morbidity and mortality worldwide. The prevalence of COPD among cigarette smokers in the Middle East is not well studied. A prospective descriptive study was performed in the north of Jordan. Male cigarette smokers ( $\geq 10$ pack-year) aged 35 years and older were recruited from the community. They completed a questionnaire and a postbronchodilator spirometry. Global Initiative for Chronic Obstructive Lung Disease (GOLD) criteria (postbronchodilator forced expiratory volume in 1 second $<70 \%$ ) was used to define COPD. A total of 512 subjects completed the study protocol. According to the GOLD criteria, 42 subjects (8.2\%) had COPD. Of those, 27 subjects $(64.3 \%)$ had symptomatic COPD. Using the GOLD criteria, eight subjects (19\%) with COPD had mild disease, $24(57.1 \%)$ had moderate disease, eight (19\%) had severe disease, and two (4.8\%) had very severe disease. Only $10.6 \%$ were aware of COPD as a smoking-related respiratory illness, and $6.4 \%$ had received counseling about risk for COPD by a physician. Chronic bronchitis (cough for 3 months in 2 consecutive years) was reported by $15 \%$ of the subjects, wheezes by $44.1 \%$, and dyspnea by $65.2 \%$. Subjects with COPD reported having more chronic bronchitis $18 / 42$ (42.9\%) and wheezing 28/42 (66.7\%) than subjects without COPD. The prevalence of COPD increased with increased number of pack-years smoked. In conclusion, COPD prevalence among cigarette-smoking men in Jordan is lower than in the developed world. COPD was largely underdiagnosed, despite the majority of participants being symptomatic and having moderate to severe disease.
\end{abstract}

Keywords: COPD, spirometry, GOLD, smoking, chronic bronchitis, Jordan

\section{Introduction}

Chronic obstructive pulmonary disease (COPD) is a leading cause of morbidity and mortality in both developed and developing countries. ${ }^{1}$ In 2001, COPD was the fifth leading cause of death worldwide; it is predicted to be the third leading cause of death by 2020. ${ }^{1,2}$ Cigarette smoking is by far the most important risk factor for development of COPD. Earlier studies reported that $15 \%-20 \%$ of smokers develop COPD, ${ }^{3,4}$ although this number may reach $50 \%$ in elderly smokers. ${ }^{5}$

COPD is a treatable and, more important, preventable disease. However, it remains underdiagnosed, ${ }^{6,7}$ and significant airflow obstruction may already be present in patients without pulmonary symptoms. ${ }^{8}$ The diagnosis of COPD should be raised in any person who reports symptoms of chronic cough, chronic sputum production, or dyspnea or who has a history of exposure to COPD risk factors (mainly tobacco smoking). ${ }^{9}$ The diagnosis of COPD in the earliest stages in smokers is crucial because quitting smoking is the only intervention that can reduce the rate of lung function decline. ${ }^{10,11}$ 
The availability of COPD spirometric data can play a role in patient management by their family doctors ${ }^{12}$ and can enhance treatment efforts. ${ }^{13,14}$

In Jordan, a recent study showed that the prevalence of current smoking in adult males was $48.2 \% .{ }^{15}$ Despite the high smoking rate, there are limited data about the prevalence of COPD and affected individuals' awareness of their diagnosis. A recent population based study in the Middle East and North Africa using telephone interview and using the Global Initiative for Chronic Obstructive Lung Disease (GOLD) clinical definition of symptomatic COPD estimated a prevalence of $5.4 \%$ of symptomatic COPD among adult Jordanians. ${ }^{16}$ We estimate the prevalence of COPD among current male smokers to be around $11 \%$.

This community-based study was conducted to describe the prevalence of COPD according to the latest GOLD definition and to describe COPD-related symptoms among adult male cigarette smokers in Jordan.

\section{Methods}

\section{Study population}

The study was conducted in the north of Jordan, which has a population of around 950,000 persons. Thirteen cities/ towns representing both rural and urban areas were selected from the Irbid governorate in the north of Jordan. One week before the survey, a two-member team visited each city, advertised the study, and invited all male current cigarette smokers aged 35 years and older to participate in the study. Ex-smokers and water pipe and cigar smokers were not included in the study. Subjects who met the study criteria were asked to complete a health history questionnaire and undergo spirometry. Subjects known to have asthma were excluded from the study. Of 650 subjects who attended the study site, a total of 512 subjects met the inclusion/exclusion criteria, agreed to participate, and completed the study protocol, including postbronchodilator spirometry. The power of the study, using a sample of 512 participants, to estimate the expected prevalence of $10 \%$ within a margin of error of $5 \%$ exceeded $80 \%$ at an alpha level of 0.05 . The data were collected during a 12-month period from January 2011 to December 2012. The study was approved by the Institutional Review Board Committee of Jordan University of Science and Technology. Written informed consent was obtained from all participants.

\section{Data collection}

Data were collected by three family physicians. During a single encounter with the physician, information about age; cigarette smoking habits, including duration of smoking and number of cigarettes smoked daily; occupation; education level; comorbidities; medication; family history of lung disease; and whether the participant had ever been diagnosed with COPD were collected in a face-to-face interview. Occupation also was reported to the interviewing physician. Occupations with exposure to heating fuels, occupational dust, and chemicals were taken into account by the interviewing physician to decide which occupations are risky for COPD. Participants were also asked to report symptoms of productive cough, wheeze, and dyspnea. The participants' height and weight were measured, and body mass index was calculated.

Spirometry was performed using handheld spirometers (FlowscreenCT; eResearch Technology GmbH, Hoechberg, Germany) and was performed and interpreted according to the American Thoracic Society recommendations. ${ }^{17}$ The instruments were calibrated before each testing day, according to the manufacturers' instructions. All spirometry was performed by two trained family physicians. The spirometry results were reevaluated and finally interpreted by a pulmonologist. Forced expiratory maneuvers were repeated until three reproducible acceptable readings were obtained and the best forced expiratory volume in 1 second (FEV1), forced vital capacity (FVC), and FEV1/FVC ratios were obtained. Reversibility testing to exclude individuals with asthma was performed 15 minutes after the inhalation of $400 \mu \mathrm{g}$ Ventolin ${ }^{\circledR}$ MDI (salbutamol; GlaxoSmithKline plc, London, UK) on all patients with FEV1/FVC $<70 \%$. The spirometry results were interpreted according to the guidelines of GOLD. ${ }^{3}$ Subjects with reversible obstruction (FEV1 increased $\geq 200 \mathrm{~mL}$ or $12 \%$ ) during the reversibility test were excluded from the study.

\section{Definitions}

COPD was defined as the presence of a "fixed ratio" (postbronchodilator FEV1/FVC $<70 \%$ ) with or without symptoms. ${ }^{3,9}$ Patients with symptomatic COPD were subjects with cough, dyspnea, or sputum production and postbronchodilator FEV1 $<70 \%$. Chronic bronchitis was defined, according to the GOLD definition, as having cough and sputum production for at least 3 months in each of two consecutive years. $^{3}$

The severity of COPD was classified, according to GOLD criteria, as stage I (mild) if FEV1 $\geq 80 \%$ predicted, stage II (moderate) if $50 \% \leq \mathrm{FEV} 1<80 \%$ predicted, stage III (severe) if $30 \% \leq \mathrm{FEV} 1<50 \%$ predicted, and stage IV (very severe) if FEV $1<30 \%$ predicted or FEV $1<50 \%$ predicted 
with the presence of respiratory failure or clinical signs of right heart failure.

\section{Statistical analysis}

Data were analyzed using the Statistical Package for Social Science (SPSS, version 16.0; SPSS, Inc., Chicago, IL, USA). Means and standard deviations of continuous variables were given. Frequencies and percentages were used to describe categorical data, and the chi-square test was for testing the association between categorical variables. One-way ANOVA was used for testing mean differences between continuous variables. Logistic regression was also used to detect the effect of the following predictors; age, pack-year of smoking, dyspnea, wheezes, and chronic bronchitis on the COPD prevalence according to GOLD criteria. $P$-values $<0.05$ were considered statistically significant.

\section{Results}

A total of 512 subjects completed the study protocol, including postbronchodilator spirometry. The mean (standard deviation) age of participants was 48.3 (10.2) years (range, 35-99 years). The body mass index of the subjects ranged between 16.5 and $51.0 \mathrm{~kg} / \mathrm{m}^{2}$, with a mean (standard deviation) of 26.8 (4.7) kg/m². Table 1 shows the demographic, anthropometric, and clinical characteristics of cigarette-smoking adults included in this study. Postbronchodilator spirometric

Table I The demographic, anthropometric, and clinical characteristics of adult cigarette smokers included in the study $(n=5 \mid 2)$

\begin{tabular}{|c|c|c|}
\hline Variable & Frequency & $\%$ \\
\hline \multicolumn{3}{|l|}{ Age, years } \\
\hline $35-44$ & 213 & 41.6 \\
\hline $45-54$ & 172 & 33.6 \\
\hline$\geq 55$ & 127 & 24.8 \\
\hline \multicolumn{3}{|c|}{ Occupation, risky for chronic obstructive pulmonary disease } \\
\hline Yes & 65 & 12.7 \\
\hline No & 447 & 87.3 \\
\hline \multicolumn{3}{|l|}{ Body mass index } \\
\hline Normal $\left(18.5-24.9 \mathrm{~kg} / \mathrm{m}^{2}\right)$ & 165 & 32.2 \\
\hline Overweight $\left(25-29.9 \mathrm{~kg} / \mathrm{m}^{2}\right)$ & 231 & 45.1 \\
\hline Obesity $\left(\geq 30 \mathrm{~kg} / \mathrm{m}^{2}\right)$ & 116 & 22.7 \\
\hline \multicolumn{3}{|l|}{ Pack-years } \\
\hline$\leq 20$ & 120 & 23.4 \\
\hline$>20$ & 392 & 76.6 \\
\hline Smoking during childhood & 233 & 45.5 \\
\hline Passive smoking & 421 & 82.2 \\
\hline $\begin{array}{l}\text { Family history of chronic obstructive } \\
\text { pulmonary disease }\end{array}$ & 38 & 7.4 \\
\hline Dyspnea & 335 & 65.4 \\
\hline Wheezes & 226 & 44.1 \\
\hline Cough for 3 months in 2 consecutive years & 77 & 15 \\
\hline
\end{tabular}

data showed an average FEV1 of $92.8 \%$ predicted and a FVC of $90.3 \%$. Only $10.6 \%$ of the participants were aware of COPD as a smoking-related respiratory illness, and $6.4 \%$ had received counseling by a physician about risk for COPD. Interestingly, eight subjects (1.6\%) were previously diagnosed with COPD, and two reported taking medications for it. Participants smoked on average 42.7 pack-years (range, 10-200) and a mean of 31 cigarettes per day (range, 4-90). Nearly half of the cigarette smokers $(45.5 \%)$ reported starting smoking during childhood. The majority of smoking men (75.6\%) received counseling for smoking cessation.

According to the GOLD criteria, 42 subjects (8.2\%) had COPD. Of those, 27 (64.3\%) subjects had symptomatic COPD. Using the GOLD criteria, eight (19\%) of subjects with COPD had mild disease, 24 (57.1\%) had moderate disease, eight (19\%) had severe disease, and two $(4.8 \%)$ had very severe disease. Subjects with COPD reported more cigarette exposure than subjects without COPD (54.6 versus 41.6 pack-years $[P=0.003]$; 30.6 versus 35.2 cigarettes per day $[P=0.046])$. The prevalence rates of COPD according to demographic, anthropometric, and other relevant characteristics are shown in Table 2. The prevalence differed significantly only among subjects according to pack-years smoked $(P=0.010)$ : The prevalence was $6.3 \%$ among adults

Table 2 The prevalence of chronic obstructive pulmonary disease among adult Jordanian smokers, according to demographic, anthropometric, and other relevant characteristics

\begin{tabular}{|c|c|c|c|c|c|}
\hline \multirow[t]{3}{*}{ Variable } & \multicolumn{4}{|c|}{$\begin{array}{l}\text { Chronic obstructive } \\
\text { pulmonary disease }\end{array}$} & \multirow[t]{3}{*}{ P-value } \\
\hline & \multicolumn{2}{|l|}{ No } & \multicolumn{2}{|c|}{ Yes } & \\
\hline & $\mathbf{n}$ & $\%$ & $\mathbf{n}$ & $\%$ & \\
\hline Total & 470 & 91.8 & 42 & 8.2 & \\
\hline Age, years & & & & & 0.733 \\
\hline $35-44$ & 195 & 91.5 & 18 & 8.5 & \\
\hline $45-54$ & 160 & 93.0 & 12 & 7.0 & \\
\hline$\geq 55$ & 115 & 90.6 & 12 & 9.4 & \\
\hline Education & & & & & 0.108 \\
\hline Illiterate & 16 & 80.0 & 4 & 20.0 & \\
\hline$\leq$ High school & 295 & 91.9 & 26 & 8.1 & \\
\hline$>$ High school & 159 & 93.5 & II & 6.5 & \\
\hline Occupation & & & & & 0.755 \\
\hline Risky job & 59 & 90.8 & 6 & 9.2 & \\
\hline Not risky & 409 & 91.9 & 36 & 8.1 & \\
\hline Body mass index & & & & & 0.869 \\
\hline Normal $\left(18.5-24.9 \mathrm{~kg} / \mathrm{m}^{2}\right)$ & 153 & 92.7 & 12 & 7.3 & \\
\hline Overweight $\left(25-29.9 \mathrm{~kg} / \mathrm{m}^{2}\right)$ & 211 & 91.3 & 20 & 8.7 & \\
\hline Obesity ( $\left.\geq 30 \mathrm{~kg} / \mathrm{m}^{2}\right)$ & 106 & 91.4 & 10 & 8.6 & \\
\hline Pack-years & & & & & 0.010 \\
\hline$\leq 50$ & 345 & 93.8 & 23 & 6.3 & \\
\hline$>50$ & 125 & 86.8 & 19 & 13.2 & \\
\hline
\end{tabular}


who smoked up to 50 pack-years and $13.2 \%$ among those who smoked more than 50 pack-years. None of the other variables was significantly associated with COPD. The multivariate yielded the same results, and only the pack-years variable remained in the model after excluding nonsignificant variables.

Chronic bronchitis was present in $77(15 \%)$ of the subjects, whereas wheezes were reported by 226 (44.1\%) and dyspnea by $334(65.2 \%)$. Both chronic bronchitis $(42.9 \%$ versus $12.6 \%)$ and wheezing (66.7\% versus $42.1 \%)$ were more common among subjects with COPD (GOLD criteria; $P<0.005)$. In contrast, dyspnea was common in subjects with and without COPD ( $81 \%$ versus $61.8 \% ; P=0.082)$.

Table 3 shows the characteristics of patients with COPD according to the severity of the disease. Severity of COPD was related to age, pack-year, and the presence of symptoms of COPD, including dyspnea, wheezes, and chronic bronchitis.

\section{Discussion}

This is the first community-based study to estimate the prevalence of COPD according the latest GOLD criteria among male cigarette smokers in Jordan. Approximately $8 \%$ had COPD, whereas according to the standard definition, $15 \%$ had chronic bronchitis. Although symptoms of COPD were common, a minority of these cigarette-smoking men already had been diagnosed, and 1 in 10 was aware of this potentially disabling disease.

Tageldin et al reported the prevalence of COPD in the general population in the Middle East and North Africa, using telephone interview and the GOLD clinical definition of symptomatic COPD. ${ }^{16}$ Their estimated prevalence of COPD was $3.6 \%$, ranging from $1.9 \%$ in the United Arab Emirates to $6.1 \%$ in Syria. In Jordan, the prevalence was $5.4 \%$ in the general population and $8.8 \%$ among adult men. ${ }^{16}$ However, their case definition of COPD was smokers ( $\geq 10$ pack-years) who had symptoms of COPD or were already diagnosed by

Table 3 Characteristics of patients with chronic obstructive pulmonary disease, according to disease severity

\begin{tabular}{llll}
\hline Variable & \multicolumn{3}{l}{$\begin{array}{l}\text { Global initiative for chronic } \\
\text { obstructive lung disease stage }\end{array}$} \\
\cline { 2 - 4 } & $\begin{array}{l}\text { Stage I } \\
(\mathbf{n}=\mathbf{8})\end{array}$ & $\begin{array}{l}\text { Stage II } \\
(\mathbf{n}=\mathbf{2 4})\end{array}$ & $\begin{array}{l}\text { Stage III/IV } \\
(\mathbf{n}=\mathbf{1 0 )}\end{array}$ \\
\hline Age, mean (years) & 48.4 & 48.5 & 56.7 \\
Pack-years, mean & 60.8 & 51.7 & 56.7 \\
Chronic bronchitis, n (\%) & $3(37.5)$ & II (45.8) & $4(40)$ \\
Wheezes, n (\%) & $3(37.5)$ & I8 (75) & $7(70)$ \\
Dyspnea, n (\%) & $3(37.5)$ & $23(95.8)$ & $8(80)$ \\
\hline
\end{tabular}

their physicians. It is very hard to make comparisons between these different findings, as the populations, methodology, and case definition were very different. However, this current study gave a different prospective in regard to the epidemiology of COPD in this developing country.

This prevalence rate among male cigarette smokers is lower than what has been reported in developed countries, including Spain (12.1\%), ${ }^{18}$ Canada (13.1\%), ${ }^{19}$ Sweden $(14 \%),{ }^{20}$ and the United States $(16 \%) .{ }^{21}$ This can be explained by the fact that our population is generally younger, with more than two thirds of our subjects younger than 60 years. In subjects who were older than 60 years, the prevalence of COPD was $13 \%$, which is similar to data from developed countries. Moreover, the interaction between genetic and environmental factors may also be attributed to the low prevalence rate of COPD in our study. ${ }^{22}$ Also, the case definition of COPD in various studies has never been uniform where GOLD criteria, British Thoracic Society criteria, symptoms-based definitions, and physician diagnosis were used..$^{20,23}$

We found that most subjects were not aware of their lung disease, regardless of the presence of symptoms. Only a minority of our subjects was already diagnosed and treated for COPD. These findings could suggest that patients with COPD are not being routinely detected in the current process of medical care in Jordan. Alternatively, our subjects with COPD might have previously been diagnosed with their lung disease but not made aware of this, or did not understand the situation when they were told about the diagnosis. Our study does not shed light on the cause of this gap. However, similar gaps have been reported in highly developed countries where two thirds or more of patients with COPD are not aware of their lung disease. This includes studies undertaken in England, ${ }^{24}$ Greece, ${ }^{25}$ Canada, ${ }^{26}$ Spain, ${ }^{18}$ and the United States. ${ }^{27}$

The best way to identify adults with COPD remains unresolved. One strategy for early detection of COPD in adult male smokers is office-based spirometric screening. This approach has been encouraged in the developed world but remains controversial. ${ }^{28,29}$ An alternative strategy endorsed by the GOLD initiative is case-finding with spirometry, targeting adults with risk factors and symptoms suggestive of COPD. In this study, chronic bronchitis definition (cough for 3 months in 2 consecutive years) was found in $15 \%$ of our patients, which is almost double the GOLD "fixed ratio" definition. Variation in the prevalence with various measuring methods is well-established in previous reports. ${ }^{29,23}$

As previously reported, ${ }^{18,24,30,31}$ we found that amount of smoking by pack-years was significantly associated with COPD. Similar to others, we found a history of 
wheezing and productive cough to be strongly associated with the presence of COPD. ${ }^{24,32}$ There was a trend between advancing age (young versus old smoker) and COPD (8\% versus $13 \%$, respectively), but it did not reach statistical significance.

COPD case finding might be an effective strategy if primary care physicians made routine use of these clinical findings to prompt further evaluation by spirometry. This approach has been shown to be cost-effective in a primary care setting in the Netherlands. ${ }^{13}$ Whether this approach allows Jordanian men with COPD to be diagnosed and informed about their lung disease at an earlier stage deserves further study.

This study has a number of limitations. COPD was defined according to the GOLD criteria and the "fixed ratio" concept (FEV1/FVC ratio $<0.70)$. Compared with using the lower limit of normal, the fixed ratio definition of COPD is known to underestimate the prevalence of COPD among younger subjects and overestimate it among older smokers. ${ }^{33}$ However, many major studies have used the fixed ratio definition, as it is more easily applicable and widely available in clinical practice. ${ }^{29}$ Smokers with respiratory symptoms might have attended the testing sessions more than asymptomatic smokers, resulting in a selection bias. It also is known that the considerable variations in the reported prevalence of COPD are attributed to different selection processes. ${ }^{29,34}$ Women were excluded from our study. For cultural reasons, women in Jordan who smoke tend not to disclose their smoking status and are less likely to participate in studies that involve sensitive issues. Tageldin et al reported the estimated prevalence of symptomatic COPD in Jordan to be five times more in men $(8.8 \%)$ than in women $(1.8 \%) .{ }^{16}$ This may indicate that in Jordan, COPD may still be primarily a disease of men, rather than women.

Although most of our subjects had been advised to stop smoking at some time in the past, this advice had not resulted in a behavior change. More effective smoking cessation activities are needed. ${ }^{35}$

\section{Conclusions}

The prevalence of COPD according to GOLD criteria among male cigarette smokers in Jordan was found to be $8.2 \%$, which is lower than in the developed countries. Although symptoms of COPD including chronic bronchitis were common, COPD was still largely underdiagnosed in such a risky population. The feasibility, benefit, and cost-effectiveness of a community-based screening or primary care case finding in Jordan using spirometry warrant further study.

\section{Disclosure}

The authors report no conflicts of interest in this work.

\section{References}

1. Mannino DM, Buist AS. Global burden of COPD: risk factors, prevalence, and future trends. Lancet. 2007;370(9589):765-773.

2. Lopez AD, Shibuya K, Rao C, et al. Chronic obstructive pulmonary disease: current burden and future projections. Eur Respir J. 2006;27(2):397-412.

3. Global Initiative for Chronic Obstructive Lung Disease. Global Strategy for the Diagnosis, Management and Prevention of Chronic Obstructive Pulmonary Disease. Workshop Report. 2009. Available from: http://www. goldcopd.org/guidelines-global-strategy-for-diagnosis-management. html. Accessed on February 22, 2014.

4. Yawn BP, Keenan JM. COPD - the primary care perspective: addressing epidemiology, pathology, diagnosis, treatment of smoking's multiple morbidities and the patient's perspective. COPD. 2007;4(1):67-83.

5. Teramoto S. 1. COPD pathogenesis from the viewpoint of risk factors. Intern Med. 2007;46(2):77-79.

6. Ohar JA, Sadeghnejad A, Meyers DA, Donohue JF, Bleecker ER. Do symptoms predict COPD in smokers? Chest. 2010;137(6): 1345-1353.

7. Tálamo C, de Oca MM, Halbert R, et al; PLATINO team. Diagnostic labeling of COPD in five Latin American cities. Chest. 2007;131(1):60-67.

8. Rabe KF, Hurd S, Anzueto A, et al; Global Initiative for Chronic Obstructive Lung Disease. Global strategy for the diagnosis, management, and prevention of chronic obstructive pulmonary disease: GOLD executive summary. Am J Respir Crit Care Med. 2007;176(6):532-555.

9. Celli BR, MacNee W; ATS/ERS Task Force. Standards for the diagnosis and treatment of patients with COPD: a summary of the ATS/ERS position paper. Eur Respir J. 2004;23(6):932-946.

10. Scanlon PD, Connett JE, Waller LA, et al; Lung Health Study Research Group. Smoking cessation and lung function in mild-to-moderate chronic obstructive pulmonary disease. The Lung Health Study. Am J Respir Crit Care Med. 2000;161(2 Pt 1):381-390.

11. van der Meer RM, Wagena EJ, Ostelo RW, Jacobs JE, van Schayck CP. Smoking cessation for chronic obstructive pulmonary disease. Cochrane Database Syst Rev. 2003;(2):CD002999.

12. Dales RE, Vandemheen KL, Clinch J, Aaron SD. Spirometry in the primary care setting: influence on clinical diagnosis and management of airflow obstruction. Chest. 2005;128(4):2443-2447.

13. O'Donnell DE, Aaron S, Bourbeau J, et al. Canadian Thoracic Society recommendations for management of chronic obstructive pulmonary disease - 2007 update. Can Respir J. 2007;14 Suppl B:5B-32B.

14. Bourbeau J, van der Palen J. Promoting effective self-management programmes to improve COPD. Eur Respir J. 2009;33(3):461-463.

15. Belbeisi A, Al Nsour M, Batieha A, Brown DW, Walke HT. A surveillance summary of smoking and review of tobacco control in Jordan. Global Health. 2009;5:18.

16. Tageldin MA, Nafti S, Khan JA, et al; BREATHE Study Group. Distribution of COPD-related symptoms in the Middle East and North Africa: results of the BREATHE study. Respir Med. 2012;106(Supp1 2): S25-S32.

17. Standardization of Spirometry, 1994 Update. American Thoracic Society. Am J Respir Crit Care Med. 1995;152(3):1107-1136.

18. Jaén Díaz JI, de Castro Mesa C, Gontán García-Salamanca MJ, López de Castro F. Prevalencia y factores de riesgo de EPOC en fumadores y ex fumadores. [Prevalence of chronic obstructive pulmonary disease and risk factors in smokers and ex-smokers]. Arch Bronconeumol. 2003;39(12):554-558. Spanish.

19. Dales RE, Aaron SD, Vandemheen KL, Mehdizadeh A, Clinch J. The prevalence of airflow obstruction in rural primary care. Respir Med. 2006;100(4):754-759. 
20. Nathell L, Nathell M, Malmberg P, Larsson K. COPD diagnosis related to different guidelines and spirometry techniques. Respir Res. 2007;8:89.

21. Price DB, Tinkelman DG, Halbert RJ, et al. Symptom-based questionnaire for identifying COPD in smokers. Respiration. 2006;73(3):285-295.

22. Molfino NA. Current thinking on genetics of chronic obstructive pulmonary disease. Curr Opin Pulm Med. 2007;13(2):107-113.

23. Halbert RJ, Isonaka S, George D, Iqbal A. Interpreting COPD prevalence estimates: what is the true burden of disease? Chest. 2003;123(5): 1684-1692.

24. Shahab L, Jarvis MJ, Britton J, West R. Prevalence, diagnosis and relation to tobacco dependence of chronic obstructive pulmonary disease in a nationally representative population sample. Thorax. 2006;61(12): 1043-1047.

25. Minas M, Hatzoglou C, Karetsi E, et al. COPD prevalence and the differences between newly and previously diagnosed COPD patients in a spirometry program. Prim Care Respir J. 2010;19(4):363-370.

26. Hill K, Goldstein RS, Guyatt GH, et al. Prevalence and underdiagnosis of chronic obstructive pulmonary disease among patients at risk in primary care. CMAJ. 2010;182(7):673-678.

27. Yawn B, Mannino D, Littlejohn T, et al. Prevalence of COPD among symptomatic patients in a primary care setting. Curr Med Res Opin. 2009;25(11):2671-2677.

28. Ferguson GT, Enright PL, Buist AS, Higgins MW. Office spirometry for lung health assessment in adults: a consensus statement from the National Lung Health Education Program. Respir Care. 2000;45(5):513-530.
29. Lin K, Watkins B, Johnson T, Rodriguez JA, Barton MB; US Preventive Services Task Force. Screening for chronic obstructive pulmonary disease using spirometry: summary of the evidence for the US Preventive Services Task Force. Ann Intern Med. 2008;148(7):535-543.

30. Buist AS, McBurnie MA, Vollmer WM, et al; BOLD Collaborative Research Group. International variation in the prevalence of COPD (the BOLD Study): a population-based prevalence study. Lancet. 2007;370(9589):741-750.

31. van Durme YM, Verhamme KM, Stijnen T, et al. Prevalence, incidence, and lifetime risk for the development of COPD in the elderly: the Rotterdam study. Chest. 2009;135(2):368-377.

32. Fromer L. Diagnosing and treating COPD: understanding the challenges and finding solutions. Int J Gen Med. 2014:729-739.

33. Hansen JE, Sun XG, Wasserman K. Spirometric criteria for airway obstruction: Use percentage of FEV1/FVC ratio below the fifth percentile, not $<70 \%$. Chest. 2007;131(2):349-355.

34. Van Schayck CP, Loozen JM, Wagena E, Akkermans RP, Wesseling GJ. Detecting patients at a high risk of developing chronic obstructive pulmonary disease in general practice: cross sectional case finding study. BMJ. 2002;324(7350):1370.

35. American Lung Association. Trends in COPD (Chronic Bronchitis and Emphysema): Morbidity and Mortality. American Lung Association Epidemiology and Statistics Unit, Research and Program Services Division; 2010. Available from: http://www.lung.org/finding-cures/ourresearch/trend-reports/copd-trend-report.pdf. Accessed February 22, 2014 .
International Journal of COPD

\section{Publish your work in this journal}

The International Journal of COPD is an international, peer-reviewed journal of therapeutics and pharmacology focusing on concise rapid reporting of clinical studies and reviews in COPD. Special focus is given to the pathophysiological processes underlying the disease, intervention programs, patient focused education, and self management protocols.

\section{Dovepress}

This journal is indexed on PubMed Central, MedLine and CAS. The manuscript management system is completely online and includes a very quick and fair peer-review system, which is all easy to use. Visit http://www.dovepress.com/testimonials.php to read real quotes from published authors. 